\title{
The Linguistic Prehistory of Japan: Some Archaeological Speculations
}

\author{
MARK HUDSON \\ Department of Archaeology and Anthropology, The Australian \\ National University, Canberra, ACT 0200, Australia.
}

Received June 4, 1993.

\begin{abstract}
This paper applies recent archaeological thinking on language dispersal and replacement to Japanese. Based on the principles summarized by Renfrew (1992a), I argue that the Japanese language spread from Kyushu with agricultural colonization in the Yayoi period (ca. 400 B.C.-A.D. 250). Some supporting linguistic evidence for this model is provided by the distribution of Japanese dialects within the archipelago. If correct, the model would seem to rule out any significant process of creolization in the formation of Japanese. Although the continental origins of Japanese are still unclear, the model may also provide linguistic support for the theory of Yayoi immigration espoused by many biological anthropologists.
\end{abstract}

Key Words: Japan, historical linguistics, archaeology, Ainu, agricultural colonization

\section{INTRODUCTION}

Recent years have seen growing interest in how linguistic data may be used to understand prehistoric population movements. Of course, linguists and some archaeologists had long published their views on this subject, particularly within the field of Indo-European studies. The active participation of archaeologists in such debates, however, is increasing, a development which can be attributed to a variety of causes. A return to consideration of the question of human migration in prehistory is one reason. Another is recent work by certain linguists on large-scale language classification which may be able to throw light on very early dispersals. A third reason is the growing potential for the integration of linguistic, biological, and archaeological data for understanding the spread of human populations. In the past few years a number of books and articles have appeared written in whole or in part by prehistorians and dealing with the "linguistic archaeology" of Europe (Renfrew, 1987; Sherratt and Sherratt, 1988; Zvelebil and Zvelebil, 1988), Southeast Asia and the Pacific (Bellwood, 1987, 1991, 1992), as well as with more general, pan-regional concerns (Renfrew, 1989, 1991, 1992a, 1992b; Bellwood, 1990, in press).

My own interest in the interface between language and archaeology stemmed originally from a desire to understand the role of immigration in the formation of 
Yayoi culture in late prehistoric Japan (cf. Hudson n.d.). In this present paper I take a more general look at what we know about the history of the Japanese language and how that can be used to throw light on the early human settlement of the archipelago. My conclusions here can be seen as support for the model of Yayoi immigration now supported by many biological anthropologists.

\section{THE GENETIC AFFILIATIONS OF JAPANESE}

Despite almost a century and a half of research there is still no consensus on the genetic affiliation of the Japanese language. Since Japanese has over 120 million speakers it thus remains the largest world language whose genetic relationships have yet to be widely agreed upon. There are several reasons for this lack of consensus. In a recent review, Shibatani notes that the major problem has been the difficulty in establishing sufficient cognates and sound correspondences between Japanese and other languages. He suggests this is due to the probable enormous time depth in which Japanese has evolved after splitting from a parent language (Shibatani, 1990, p.117). Many Western linguists, however, have convincingly argued that the comparative method is so rarely taught in Japanese universities that unfamiliarity with that method must also be counted as a reason (Miller, 1980, pp. 44-45). Perhaps even more serious is a common propensity amongst Japanese scholars to see their language as so unique as to be unsuited for study using the traditional methods of historical linguistics:

[The] difference in the attitudes of modern Korean and modern Japanese scholarship towards questions of the genetic relationship of their respective languages is more a reflection of national temperament, and of the different ways in which both nations view problems of national identity, that it is of different linguistic materials. Korean scholarship has been less afraid to surrender its national identity in the direction of a clear-cut Altaic relationship than has its Japanese opposite number; for modern Japan, any acknowledgment of far-reaching linguistic relationships has seemed a surrender of identity for which the culture is still unprepared.

(Miller, 1992, p. 17, emphasis added)

A further problem is the way some Japanese linguists have based their theories around a priori assumptions concerning the historical and archaeological records. Examples of this will be given in the next section. One should be careful not to give the impression that all faults lie with Japanese scholarship and all the answers with the West, yet it seems fair to say that Japanese beliefs about their language have played an integral part in questions of Japanese identity and nationalism and that linguistic scholarship has suffered as a result (see Miller, 1982).

Three main types of theories have been proposed with regard to the genealogy 
of Japanese:

(1) Theories proposing a genetic link with the Altaic family

(2) Theories proposing a genetic link with South/Southeast Asian or Pacific languages (mainly Austronesian)

(3) Theories which see Japanese as some sort of mixed language (mainly Austronesian-Altaic)

In practice these three theories may be further condensed to two as most linguists who argue for an Austronesian link also support a relationship with Altaic, leading to the concept of a mixed language.

Of the three theories, the first has the longest and most respectable pedigree. The Austrian Anton Boller began comparative work on Japanese in the 1850s with the proposition that Japanese is related to the Altaic family of languages (Boller, 1857). Altaic is a widely dispersed family with around 60 languages spoken by some 250 million people (Ruhlen, 1987, p. 127)1. It was first classified in 1730 by von Strahlenberg who posited a Tatar family comprising Finno-Ugric, Turkic, Samoyed, Mongol-Manchu, Tungus and Caucasian. Nineteenth-century linguists removed Caucasian and placed Manchu with Tungus rather than Mongolian; otherwise von Strahlenberg's original conception stood the test of time quite well. Instead of Tatar the group was now known as the Uralic-Altaic family comprising an Uralic subgroup of Finno-Ugric and Samoyed and an Altaic sub-group of Turkic, Mongolian and Tungus. The 20th century has seen two main developments with regard to this family. Firstly, the link between Uralic and Altaic has been increasingly questioned, and secondly a great deal of work has been conducted attempting to link Japanese and Korean with the Altaic family (Ruhlen, 1987, pp. 127-135). Korean had been linked with Altaic in the early 19th century and this was later supported by the research of Aston (1879), Ramstedt (1949), Poppe (1960), Lee (1964) and others (see Lewin, 1976). It was not until 1966, however, that a body of more than 300 etymologies connecting Korean and Japanese was published by Samuel Martin. A few years later another North American linguist, Roy Andrew Miller (1971), attempted to show that Japanese also belongs within the Altaic group, a conclusion given further support by Menges (1975) and Starostin (1986, 1991).

Despite this work, Altaic classification still remains controversial and at present there seem to be two conflicting views on Japanese and Altaic within the Western linguistic community. What may perhaps be termed the orthodox view supports a proto-Altaic unity as reconstructed by Ramstedt and Poppe; this original language then split into the Turkic, Mongolian and Tungusic divisions mentioned previously. Japanese and Korean are regarded to have branched from an early eastern division

1 This is the total including Japanese which thus accounts for almost half of the speakers of Altaic languages (Ruhlen, 1987, p. 127). 
of this family. One of the most influential supporters of this view is Roy Andrew Miller, a prolific and persuasive writer whose work has become extremely wellknown to archaeologists and others outside of the linguistic community. A contrasting view, however, sees the traditional Altaic classification as premature. Central to this criticism is the validity of a genetic relationship between Turkic, Mongolian and Tungusic and thus the whole concept of an original proto-Altaic linguistic unity. Summarizing a recent conference discussion, J. Marshall Unger (1990a, p. 479) writes that, "Indeed, as far as Japanese and Korean are concerned, we are not even sure that bringing Mongolian into consideration, let alone Turkic, is worthwhile given the present state of knowledge." With regard to Japanese, Unger suggests that work should be directed to the reconstruction of what has been termed the Macro-Tungusic group of Northeast Asia.

In Japan itself the perceived scarcity of convincing cognates between Japanese and the Altaic languages, and the phonological simplicity of Japanese, have led many linguists to look to the south rather than the north. In particular, phonological similarities with the Austronesian languages have determined the main source of comparisons. This "southern hypothesis" cannot be understood on linguistic criteria alone. It derives at least in part from a wider debate on Japanese cultural origins wherein the apparent opposition of tropical and temperate cultural traits is interpreted as the result of the mixing of various waves of migration from the north and south. It is not surprising, therefore, that most linguistic theories in this category also postulate a mixing of Austronesian and Altaic languages in the formation of Japanese.

In particular, the concept of linguistic "strata" has been very popular in Japan. This refers to the replacement of an original language (the substratum) by a later language (the superstratum) with some degree of influence held over from the first language. Building on earlier work by Shinmura (1911), Polivanov (1924) and Izui (1952), Ono Susumu appears to have been the first linguist to propose an Austronesian substratum in the sense that an Austronesian language had once been spoken in the Japanese archipelago (see Shibatani, 1990, pp. 103-107). In other words, rather than a single genealogical link influenced by borrowing (the view of Izui), Ono sees a series of languages which replaced each other, though with some elements retained between each stage. In the late 1950s Ono proposed a two-stage model of an original Austronesian language followed by an Altaic language in the Yayoi period (Ono, 1970). By 1980 he had inserted a third language (Tamil, a Dravidian language of south India) into his scheme. At first Ono (1980) argued that Tamil arrived in the middle of the Jomon, but has since changed this to the Yayoi period (Ono, 1990; cf. Hudson, 1992).

Another major figure in Japanese linguistics has been Murayama Shichiro. Unlike Ono, Murayama (e.g., 1976) supports the view of Japanese as a "mixed language" 
with an earlier Austronesian element influenced by Altaic forms. Although this idea of Japanese as a mixed language was first proposed by the Soviet scholar E.D. Polivanov (1890-1938), it has found most support amongst Japanese linguists. In Japan one often comes across the opinion that Japanese is such a unique language that its historical development must have also followed uniquely complex processes. Because of such polemical posturings associated with the concept of mixed languages, many Western linguists have dismissed the concept. This may have blinded us to the importance of considering what happens in language contact situations, something Maher (1991) has recently tried to remedy by an explicit consideration of the sociolinguistic aspects of Yayoi language change. Maher's "North Kyushu Creole" hypothesis will be discussed in more detail below.

The theory of a genetic relationship between Japanese and Austronesian has not only been confined to Japanese scholars. In addition to several early works (e.g., Whymant, 1926), particular mention should be made of Benedict's 1990 book Japanese/Austro-Tai. Through a series of proposed phonological correspondences Benedict attempts to show that Japanese and Austronesian share a common ancestor ("Austro-Japanese"). Benedict ignores the competing Altaic hypothesis and describes Japanese solely in terms of his Austro-Tai link, but in a review of the book Solnit (1992) tabulates Benedict's Austronesian cognates with Altaic cognates proposed by Starostin (1986). Solnit (1992, p. 194) concludes that the results "seem to mirror the notion of co-existing Austronesian and Altaic strata in the Japanese lexicon."

Table 1. Comparison of proposed cognates of basic Japanese words

\begin{tabular}{lcc}
\hline Austronesian cognates only: & 31 & $28 \%$ \\
Altaic cognates only: & 45 & $40 \%$ \\
Competing: & 25 & $23 \%$ \\
Missing altogether: & $\underline{10}$ & $9 \%$ \\
Total: & 111 & \\
\hline
\end{tabular}

From Solnit (1992, p. 194)

\section{LANGUAGE AND ARCHAEOLOGY: EXPLAINING THE LINKS}

Linguists, both in Japan and in the West, have proposed various scenarios to explain their view of the history of the Japanese language. A basic difficulty has been that while most agree Korean is the closest known language to Japanese, differences between the two modern languages imply that they split many millennia ago and could not have diverged from a common ancestor as recently as the Yayoi period (ca. 400 B.C.-A.D. 250). This is a rather disturbing situation, seemingly 
negating the neat hypothesis of Yayoi immigration supported by the biological evidence (cf. Dodo and Ishida, 1990; Hanihara, K., 1991). Linguists have tried to get around this problem in one of two ways - either by assuming Japanese is a mixed language of some sort, or else by positing the evolution of Japanese in a geographically limited area of the archipelago or peninsula.

Miller (1980) looked for evidence of a pre-Yayoi migration into Japan from the Korean peninsula which might have been associated with the divergence of Japanese and Korean. He believed he found such evidence in the Early Jomon comb-pattern ceramics of Kyushu. Miller concentrated on the Sobata type of the late Early phase, but it is also worth considering the Todoroki B applique ware from the first half of that phase. These two types, which date roughly to the 4th millennium B.C., have been linked with ceramics of the Korean peninsula since before the war (Oikawa, 1933). Further similarities between composite fishhooks on both sides of the Tsushima Straits have led Komoto (1986) to suggest groups of fishermen may have arrived in Kyushu from the peninsula at this time. Komoto linked this population movement with the eruption of the Kikaigashima volcano off Kagoshima at about 4400 B.C. Ash from this eruption, known as the Akahoya deposits, has been traced as far as eastern Japan and is one meter thick in southern Miyazaki. The pottery from below the Akahoya layer is known as the Senokan type. After the fall of the ash deposits, "Senokan-type pottery disappeared and new types of pottery named Todoroki ... appeared, suggesting extensive cultural ruin and the arrival of new migrants" (Yasuda, 1991, p. 155). Komoto (1986, p. 112) has even suggested that most of the inhabitants of Kyushu may have been killed by ash and tsunami following the Kikaigashima eruption.

Recently Mizunoe (1992) has also argued that the development of the Sobata type marked an important cultural dividing-line in Kyushu. Influence from the peninsula is clear, but Mizunoe stresses local continuities. It is perhaps not irrelevant to point out that, like most Japanese archaeologists, Mizunoe's approach is strictly typologi$\mathrm{cal}$ and is not designed to model population interaction. It seems to me that one could probably argue for some migration from the Korean peninsula into Early Jomon Kyushu, but it is not as clear-cut as Miller suggests. Just as there is no necessary relationship between race and language (cf. Miller, 1982, pp. 144-64), there is also no inherent reason why a particular artifact or style should be linked with a certain social group. If the Early Jomon culture of Kyushu was totally replaced by a contemporary culture from southern Korea then population replacement would be a reasonable explanation: but that was not the case either at the Todoroki or Sobata stage. Takahashi (1989), for example, has argued for typological continuity between Todoroki pottery found both below and above the Akahoya ash layer. Of course it is impossible to prove that a new language did not arrive in Japan at this time, but Jomon Kyushu had many contacts with the mainland and perhaps we need to 
turn the problem around and look at when the cultures of Kyushu and the southern peninsula were no longer in frequent communication to determine when the languages diverged.

Though it is by no means impossible that Japanese arrived in Kyushu in the Early Jomon, Miller's explanation for the spread of that language to the rest of the archipelago is less convincing. From Kyushu Miller (1980, pp. 125-30) argues that comb-pattern pottery spread slowly east, reaching the Kinai in the Middle Yayoi (ca. 100 B.C.-A.D. 100). This interpretation is based on the presence of comb decoration on ceramics in the Kinai region from this time. Like many early archaeologists, Miller makes the easy mistake of equating a decorative technique with a culture and thus a people and a language, talking about a "comb-pattern population and its culture" (Miller, 1990, p. 20). The spread of comb decoration from the Kinai in the Middle Yayoi, therefore, is seen as the intrusive spread of a new ethnic group (Miller, 1990, p. 21). Although comb-pattern pottery was the major diagnostic trait of this Japanese speaking culture, we are asked by Miller to imagine a scenario in which the culture expands slowly out of Kyushu from about 3000 B.C., does not produce comb ceramics along the way, but suddenly re-discovers the technique in the Kinai after about 100 B.C. The proposed comb-pattern culture is defined solely on the basis of a single decorative technique, but the basic technology of comb decoration would not have been difficult to re-invent many times and there is no reason to assume the two occurrences have any sort of ethnic significance. Furthermore, there are major differences between the comb decoration techniques of Early Jomon and Middle Yayoi ceramics.

As already mentioned, recent work by Maher (1991) has taken a sociolinguistic perspective on language change in the Yayoi. Maher starts from the assumption that substantial migration into Japan occurred in the Yayoi. I believe that this is a reasonable assumption, although we might argue about what sort of numbers we are dealing with. In any case, there are surely few scholars who would argue that no migration whatsoever happened in the Yayoi and we are thus forced to consider how the language(s) of the immigrants interacted with the language(s) of the Jomon people. Building on earlier work by Chew (1976, see also 1989) and Kawamoto, Maher suggests that a creole developed in north Kyushu which spread through the archipelago.

A number of comments can be made about Maher's hypothesis. Firstly, I find unconvincing his suggestion that a variety of languages were spoken in the Jomon which was "composed of languages from the north (Palaeosiberian), the south (Malayo-Polynesian) and the west from China and Korea (Proto-Altaic)" (Maher, 1991, p. 15). Of course this is not something about which one can be certain, but Maher's (1991, p. 29) mention of cultural influences from the south, for instance, in no way represents evidence of a linguistic relationship with Malayo-Polynesian. 
It is my feeling that languages from so many different families are unlikely to have existed in what was a relatively isolated Jomon archipelago. Another problem is the relationship with Ainu. Both Maher and myself see Ainu as a descendant of a Jomon language (see below), but Maher's scheme lacks an explanation of why the other Jomon languages became creolized so easily (or else died out) but Ainu alone remained separate. Lastly, and more generally, I fail to be convinced that Yayoi language contact led to a creole rather than language replacement, perhaps with a limited amount of borrowing. Recent work by several archaeologists, including Bellwood (1990, 1991, in press) and Renfrew (1987, 1991, 1992a, 1992b) has suggested that agricultural colonization is perhaps the major cause of language replacement and rarely if ever leads to creolization. The theoretical underpinnings of this view will be discussed below, but I believe the Yayoi to be just such a case of agricultural expansion and see language replacement as a far more likely scenario than mixing of any sort.

Despite these criticisms, among Western linguists Miller and Maher have shown some of the greatest interest in integrating the archaeological and linguistic data for Japanese. ${ }^{2}$ The comments of many other Western scholars have been little more than speculation based often on a poor understanding of the archaeological record. To take one recent example, Unger (1990b) suggests the answer to the problem of the origins of Japanese lies in Egami Namio's Horserider thesis - or more precisely in Ledyard's (1975) reinterpretation of that theory. Although Unger is aware of the criticism (developed in English by Walter Edwards, 1983) that continental grave goods do not appear until about 90 years after the proposed invasion, he writes that this is "more or less what one would expect. If continental grave goods appeared exactly around the time that Ledyard postulates for the Puyo invasion, his theory would be in real trouble; the data compiled by Edwards, far from disconfirming the so-called 'horserider' theory, seem to corroborate it" (Unger, 1990b, p. 551). Although no explanation is given for this unusual line of reasoning, it leads Unger to suggest that Japanese arrived with Puyo invaders in the Kofun period. Unger seems unaware of the more general criticisms that have been levelled at the Horserider theory (e.g., Barnes, 1988, pp. 16-24) and few serious historians now support that particular view of Japanese state formation.

Unger's overall approach is similar to the language strata favored by Japanese scholars in that he posits a three-stage scheme with a (possibly Tungusic) Jomon language or languages replaced by a (possibly Austronesian) language or languages in the Yayoi which was again replaced by proto-Japanese in the 4th century A.D. I have already mentioned that interest in language strata and mixing derives partly

2 Miller, in particular, has long been a strong advocate of combining linguistic and archaeological approaches in his many publications. 
from cultural anthropological theories on Japanese origins in general. We can trace the roots of this approach back to the Kulturkreis school of European anthropology which Oka Masao was mainly responsible for bringing back to Japan. Put simply, Oka suggested that Japan had been settled by successive waves of migratory peoples who brought with them the various cultural traits that made up historic Japanese civilization. In his unpublished 1933 University of Vienna doctoral dissertation Oka proposed five main components, summarized in Obayashi (1991, pp. 4-5):

(1) A Melanesian-type culture from the South Pacific in the Middle Jomon

(2) An Austroasiatic-speaking group from south China bringing upland rice cultivation in the late Jomon

(3) A Northeast Asian group bringing an Altaic language in the Yayoi

(4) A group from coastal south China, probably of Austronesian origins, bringing wet rice agriculture

(5) An Altaic-speaking militaristic group from Northeast Asia which subjugated Japan from the 3 rd to 4 th centuries A.D.

It is important to note that while Oka is making explicit linguistic hypotheses, he is not using linguistic data but a priori assumptions about the origins of cultural traits such as rice farming. The influence of Oka's approach can still be seen in Japan nearly fifty years after his original work (e.g., in Sasaki, 1991).

It would easily be possible to write a whole monograph just summarizing the various theories on the origins of Japanese. Before this section turns into such a work, I will finish with a few concluding comments. A number of scholars have suggested that because Jomon culture shows strong northern characteristics, a northern type of language was spoken at that time. There is good evidence, however, that the Jomon people were physically of southern origin (or at least were similar to late Pleistocene and early Holocene populations in Southeast Asia; see Hanihara Kazuro, 1991) and we could equally argue that a "southern" type of language was used. This sort of simplistic, non-linguistic argument is misleading. Cultures are not solid blocks of attributes; cultural traits can and are discarded and adopted through history. To take one concrete example, the semi-subterranean pit-houses used in the Jomon period are often regarded to be adaptations to a cold climate showing the Jomon people came from the north; similarly, the raised-floor buildings of the Yayoi and the flimsy wooden houses of traditional Japan have suggested southern roots to many writers. Whymant (1926, p. 50) began his "Oceanic Theory of the Origins of the Japanese Language and People" with such observations:

... the Japanese house is the Malayan and Polynesian house.... The Japanese have kept unwaveringly to the same form of dwelling from the beginning; we have no evidence at all of change. They are invaders here, they must have brought it with them, since the Ainu are not builders, ergo, they came from 
the south bringing with them the only structure they knew, the light open structure built upon piles.

The reality is much more complex. Although the raised floor storehouses of the Yayoi period possibly diffused from China or Korea, pit houses were built in Japan until the Heian period or later. ${ }^{3}$ In Hokkaido pit houses were constructed until the end of the Satsumon period after which there was a switch to above-ground structures (Fujimoto, 1988, p. 52). Looking only at the late historic Ainu we might easily assume such buildings are evidence of their "southern" origin; the ancestors of the Ainu, however, dug warm pit houses and we need to look at why such changes occurred in more detail.

What has been missing from all these previous works is any sort of consideration of language change and human dispersal from an archaeological or anthropological perspective. Of course this is a general problem which has plagued discussions of linguistic prehistory in many parts of the world. Recently, however, Colin Renfrew has attempted to develop a theory of linguistic change in prehistory (Renfrew, 1989, 1992a, 1992b). Renfrew's four categories of language replacement are given here in full since they will be of central importance in the discussion to follow:

(a) Subsistence / demography model, where large numbers of people speaking the new language move into the territory. They do not conquer by force of arms but are able to settle because they are possessed of a subsistence adaptation which either occupies a different ecological niche from that of the earlier population, or is significantly more effective and productive within the same niche through the possession of some technological advantage.

(b) Elite dominance, where an incoming, minority elite is able, usually by military means, to seize power within the territory. This implies that the incoming group will have some centralised organisation (that is, a stratified or highly ranked structure), and often that the group conquered will have some ranking also.

(c) System collapse, where the collapse of a highly centralised (state) society leads to instability on its perimeter and to significant local movements of people and of power. Such was the position in the late days of the Roman Empire and their aftermath, the so-called "migration period." Here again the pre-existence of a stratified or state society is a precondition.

(d) Lingua franca, where a trading language (pidgin) develops within the territory as the result of intense trading or other activity by outsiders. The pidgin is usually a simplified version of the outsider language, and a creole may develop, spoken by many of the inhabitants as their natal tongue.

(Renfrew 1992a: 15-16)

3 Recently, however, finds of above-ground pillared buildings in Jomon sites are increasing. 
In the next section I suggest that the first of these categories - the subsistence/ demography model - may help us explain language replacement with agricultural colonization in Japan during the Yayoi period. The Yayoi (ca. 400 B.C.-A.D. 250) was Japan's first full-scale farming culture (Hudson, 1990; Pearson, 1992, pp. 12953). The degree of continental immigration in the Yayoi has always been controversial but recent biological data suggests migrants were numerous (e.g., Dodo and Ishida, 1990; Hanihara, K., 1991). Even if they were initially a minority, however, we know from other parts of the world that agricultural societies can reproduce and expand at a vigorous rate and that such expansion often goes hand-in-hand with language replacement (Renfrew, 1992b, pp. 455-57; Bellwood, 1990, in press; Shnirelman, 1988, 1989).

Of the other three categories, the concept of lingua franca has played an important part in previous thinking about the history of Japanese. As Renfrew points out, however, such pidgins and creoles are not formed easily and are the result of particular circumstances: "It is doubtful if any long-lasting creole languages came into existence before the formation of major imperial powers" (Renfrew, 1992a, p. 22). It is for this reason that I remain skeptical of the Mischsprache so favored by Japanese scholars. It's not that mixed languages never occur, it's just unlikely that they became widespread in prehistoric or early historic Japan.

Renfrew's second category - elite dominance - is also of relevance to the Japanese case. Egami's thesis that a group of horse-riding nobles, ultimately of north Korean (Puyo) origins, came to dominate Japan in the 5th century A.D. still holds a fascination for some linguists (e.g. Kazar, 1980, 1989; Unger, 1990b). Linguistically it does represent a possible scenario for language replacement and has the added advantage of explaining links between Japanese and the north Korean languages to be discussed below. Archaeologically, however, the Horserider theory has little or no supporting evidence and must therefore be discounted as a case of language replacement through elite dominance.

\section{LANGUAGE CLASSIFICATION WITHIN THE JAPANESE ARCHIPELAGO}

Most studies attempting to provide cultural explanations for the observed linguistic patterns have revolved around the possible relationships of Japanese with larger language families such as Altaic and Austronesian. In this section I want to take a slightly different approach and look at language and dialect divergence within the Japanese archipelago. I believe this approach leads to several interesting hypotheses about the linguistic prehistory of Japan.

For me the most noticeable thing about the Japanese archipelago is the comparative lack of linguistic variation. Of course, there are many dialects of Japanese (some of which are said to be mutually unintelligible) yet basically there are only three 
languages: Ainu, Japanese and Ryukyuan. Many Japanese linguists assume Japanese has a long history stretching back into the Jomon period for 10,000 years or more (e.g., Sakiyama, 1989, p. 169). The present linguistic conformity of the archipelago, however, does not seem easily reconciled with such a time depth. If there had been no language replacement in Japan since the first Paleolithic occupation then we might expect a situation rather like New Guinea where there are over 600 languages (see Crystal, 1987, p. 317). If the Japanese archipelago had a similar ratio of languages per square kilometer as New Guinea then there would be about 300 "Japanese" languages instead of only three.

Let us begin with Ainu which is the language of the native people of Hokkaido, the Kuril Islands and southern Sakhalin. Over the years Ainu has been linked with many languages and families including Hebrew, Assyrian, and Indo-European. Although Basil Chamberlain (1887) and later Kindaichi Kyosuke (1937) argued Ainu is not related to Japanese, Hattori $(1959,1964)$ and others have maintained the possibility of a distant genetic link. A number of scholars have suggested a link with Austronesian (e.g., Gjerdman, 1926; Murayama, 1992). Patrie (1982) concluded that Ainu, Japanese and Korean form a sub-group within Altaic but that Ainu is closer to Korean than Japanese.

The genetic relationship of Ainu can only be approached through linguistic evidence; we can, however, use cultural data to test the hypothesis that Ainu, or an earlier form of Ainu, was used in the Jomon period. I believe there is a good possibility that this was the case for the following reasons. Historical records imply the language spoken by the so-called Emishi of northeast Honshu was not Japanese. Several early texts mention the presence of interpreters used by the central government which was engaged in military conflicts with the Emishi (see Fukuda, 1965, pp. 5-8, pp. 34-37). From these records we know that the language of the Emishi was clearly different from the Japanese then spoken in the rest of the archipelago. Toponymic research may enable us to link the Emishi language with Ainu. It has long been suggested that many Tohoku place-names are derived from Ainu. In Hokkaido a large number of place-names are corrupted Japanese versions of Ainu words (e.g., Yamada, 1982-83). Names ending in -nai and -betsu (e.g., Wakkanai, Noboribetsu) are especially common and are derived from two Ainu words for "river," nai and pet. Place-names with these endings are also widely distributed through north Tohoku (Fig. 1). Other Ainu derivative forms are also known but, because we only have detailed knowledge of the Ainu language from the 19th century, there are probably many more such names in the Tohoku (and possibly in the rest of Japan) whose origins have been lost. A further link here is through the so-called matagi hunters, who existed in Tohoku until recent times, and used several Ainu words in their specialist vocabulary (Kudo, 1989, p. 134).

Kudo $(1989$, p. 135) writes that there is no possibility that Tohoku Ainu place- 


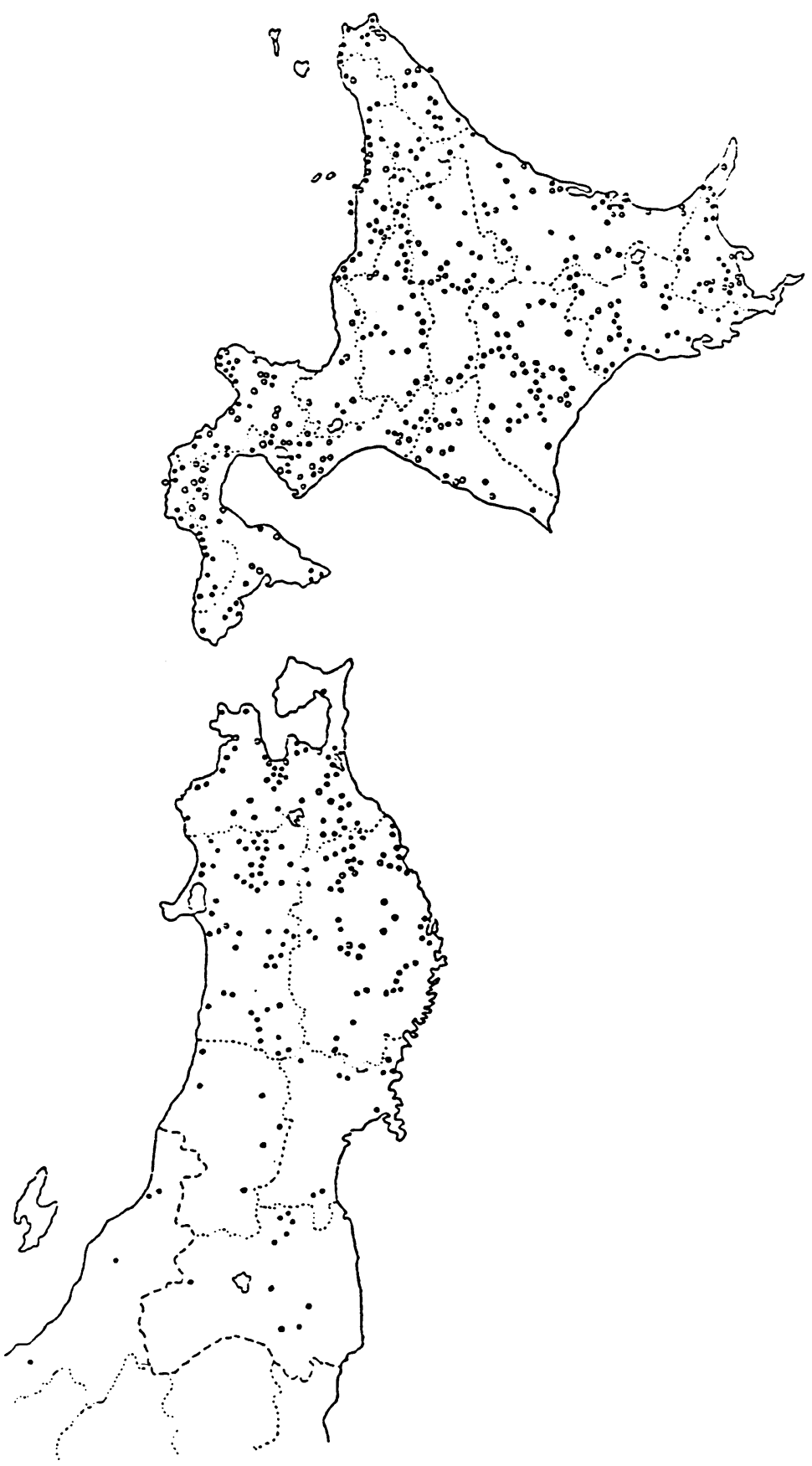

Fig. 1. The distribution of Ainu place names. Closed circles denote places ending in nai, open circles those ending in betsu. (from K. Kindaichi, "Okushu Emishi Shuzoku Ko," Gotoh Museum of Art, 1962). 
names were formed in the medieval or later periods. It seems safe to assume, therefore, that a language spoken in Tohoku from at least the Nara period was an earlier form of Ainu. Bearing in mind the cultural continuities visible over this general time period, it does not seem too much of a leap in the dark to suggest that this ancestor of Ainu may have been spoken in the Jomon period. Naturally this does not rule out the possibility that other languages were also spoken at that time.

If Ainu were descended from a Jomon language then the replacement of similar (or quite different) Jomon languages in the western and central archipelago in the Yayoi would seem a very parsimonious way of linking the biological evidence for Yayoi immigration with the linguistic data for northern Japan. The spread of the Japanese language into Hokkaido only occurred on any substantial scale with the agricultural colonization of that island by the mainland Japanese in the 19th century. Support for the arrival of a new language in the Yayoi is, I believe, provided by the history of Japanese dialects.

Let us first consider Ryukyuan, the language of the Okinawan Islands. Ryukyuan clearly holds a close genetic relationship with Japanese, so much so that most Japanese linguists see the former as a dialect of Japanese. Ryukyuan and Japanese are thought to have split from a common ancestor probably as recently as the early centuries A.D. The earliest Ryukyuan texts date to the early 16th century and little is known for certain about the earlier history of the language. For Miller (1980), Ryukyuan, Old Japanese and Middle Korean are separate offshoots from a ProtoKorean-Japanese stock. Since Japanese and Ryukyuan are clearly much closer to each other than they are to Korean, however, Japanese linguists such as Hattori (1976) prefer a later branching from a separate Proto-Japanese group. Hattori (1954) proposed a glottochronological date for the separation of the Kyoto and Shuri dialects of Japanese and Ryukyuan at between about 1450 and 1700 years ago. He later revised this to between 1500 and 2000 years ago (Hattori, 1976). Discounting a move in the opposite direction, Hattori argued that the split between the two languages was caused by a population movement from mainland Japan (Hattori, 1976, pp. 43-45). Hokama (1977, pp. 192-4) agrees with Hattori's basic conclusions, noting that Ryukyuan has attributes of 8th century or even earlier Japanese, implying a similar date of separation to the glottochronological estimates. Hattori (1976, p. 21) in fact argues that Ryukyuan and mainland Japanese cannot be derived from the 8th century Nara dialects of the early historical records. In other words their common parent language must have existed before the Nara period. On cultural grounds it is thought unlikely that the split could have occurred before the Yayoi (Kamimura, 1965, p. 58).

As regards mainland Japan, i.e., the islands of Kyushu, Shikoku and Honshu, there is a large literature on the dialectal variations found there (Miller, 1967, pp. 141-71; Shibatani, 1990, pp. 185-214). A tripartite division of dialects into Kyushu, 
western Japan, and eastern Japan is usually recognized, although as a whole Kyushu falls into the western Japan branch. The eastern dialects are known to be at least as old as the Nara period since the Man'yoshu of 759 includes poems known as the Aduma uta and Sakimori uta which include dialect forms quite different to those of the capital. An historical understanding of Japanese dialects is complicated by later developments. After the country became centralized in the 8th century the speech of the capital (Kyoto after 794) was the most prestigious and elements of Kyoto dialect spread both east and west. The presence of certain eastern dialectal traits in western Japan, however, suggests that the eastern dialect may have originally been used throughout the archipelago (Shibatani, 1990, p. 200). The speech of the capital then spread out in a wave-like pattern; regions which retain historically older dialect forms (Tohoku, San'in, Hachijojima, Kyushu and the Ryukyus) are those that have traditionally been least influenced by the capital (Shibatani, 1990, p. 207).

For our present purposes this late spread of Kyoto speech is quite irrelevant. In a different approach, Inoue (1992) compared the amount of independent dialectal forms with the degree of usage of "standard" Japanese for each prefecture. Within mainland Japan he found that Kyushu and the Tohoku both made the least use of standard speech. Of these two, however, the Tohoku also had a low level of divergent dialect forms. Ruling out geographical and social factors, Inoue convincingly explains this situation as a result of the comparatively late settlement of the Tohoku by Japanese speakers associated with the expansion of the Yamato state in the Kofun, Nara and Heian periods.

If the Yayoi expansion model were correct then we would expect the following scenario: proto-Japanese speakers spread from northern Kyushu during the Early Yayoi (ca. 300-100 B.C.). They reached the Nagoya area very quickly. Until recently archaeologists thought that Yayoi expansion further east occurred at a much slower rate. We now know Yayoi culture spread to parts of eastern Honshu almost immediately, but the role of population movement in the east remains controversial. A slower spread of the Japanese language into the Chubu, Kanto and especially the Tohoku regions would, of course, be consistent with the dialect data presented above. In this scenario Ryukyuan would have split from the Kyushu dialect in the Yayoi period.

My (admittedly non-specialist) reading of the Japanese dialect evidence is that some support for this model can be found. One expectation for which I have not found support is that the north Kyushu dialect should be the oldest form of Japanese. Particularly if Japanese arrived in Kyushu in the Early Jomon (Miller's Sobata theory) but only spread to the rest of Japan in the Yayoi, we would expect quite noticeable variations between Kyushu and other dialects. The apparent lack of such major variations may imply Japanese arrived in Kyushu at the very end of the Jomon 
and then spread almost immediately to the other islands. This would agree with the biological evidence for immigration at that time. The problem here, of course, is the source of the new language. As already noted, modern Japanese and Korean are considered too different to have split from a common ancestor only two thousand years ago. A possible way around this problem may be the fact that Old Japanese is believed to have been closer to the language of the Korean state of Koguryo that to that of Silla from which modern Korean is derived. Koguryo was destroyed by Silla in 668 A.D. (Barnes, 1990, pp. 126-31), but a number of historical records relating to the kingdom remain. In contrast, next to nothing is known about the Koguryo language. The 3rd century Wei zhi mentions that the languages of Koguryo, Puyo, Okcho, Ye, and Maek were very similar. These are all known "kingdoms" in northern Korea or Manchuria, but only Koguryo has left any substantial textual material (Lewin, 1973, p. 23).

Most of our knowledge of the Koguryo language derives from place-names preserved in the 12th century Samguk sagi. Of course, as Lewin (1973, p. 23) reminds us, "many of the reconstructed Koguryo words are hypothetical, and the reconstructions given by Korean and Japanese scholars differ in their sound shape. Moreover the probability of false identifications is relatively high, for a good many correspondences are supported by only one example." Nevertheless, some 80 Koguryo words have been reconstructed and of these as many as 34 can be compared with Old Japanese (Lewin 1976, p. 408). Lewin (1973, 1976) provides useful summaries of the Koguryo connection, but much of the original work was done by Yi Kimun [=Lee Ki-moon] and Murayama Shichiro. A sample of the correspondences is given in Table 2.

The agreement of four numerals here is particularly remarkable; the others have not been preserved but may also have been closely related. Of course it is not impossible that some of these words are borrowings. Koguryo immigration to Japan

Table 2. Koguryo and Old Japanese comparisons

\begin{tabular}{ll} 
Koguryo & \multicolumn{1}{c}{ Old Japanese } \\
*mil 'three' & mi 'three' \\
*uc 'five' & i-tu 'five' \\
*nanïn 'seven' & nana 'seven' \\
*tök 'ten' & töwö 'ten' \\
*papa 'mother' & FaFa [<*papa] 'mother' \\
*kus 'child, boy' & ko 'child' \\
*tan 'valley' & tani 'valley' \\
*wus 'cow' & usi 'cow' \\
*i 'enter' & ir- 'enter' \\
*kap(pi) 'gorge, hole' & kaFi [<*kapi] 'gorge, mountain cleft' \\
\hline
\end{tabular}

From Lewin (1973, pp. 24-25). 
is attested by archaeological, textual and place-name evidence, particularly in the central mountains in the late Kofun and early historic eras (e.g., Kirihara, 1989). The ancient name of Yamanashi, i.e., Kapï, is thought to mean "gap in the mountains" and is probably related to the Koguryo word *kap(pi) of the same meaning. The similarity of so many basic words, however, makes a genetic relationship more likely than borrowing and "it can be assumed that Japanese was closely related to the Koguryo language and that in its core it belonged to the Puyo group, or was at least close to it" (Lewin, 1976, p. 408).

Although I was critical above of Unger's (1990b) acceptance of the Horserider theory, I find it interesting that he is able to suggest an arrival of Japanese as part of this Puyo-Koguryo group as late as the early centuries A.D. There are a number of obvious problems, however. Firstly, since modern Korean and Japanese, the only existing representatives of the Puyo-Han group, are so different a considerable history of separation on the Korean peninsula is implied after the original split of the two groups. More difficult to explain is their geographical inversion. The Han languages were spoken in the south and the Puyo languages in the north of the peninsula. Although some Paekche aristocracy may have come from Puyo or Koguryo, Yayoi-period archaeological links were mainly with the south. Ro's (1992) recent suggestion that bronze-using people from the northern peninsula moved south during the Korean Bronze Age (ca. 500-200 B.c.) is of relevance here, but more work is needed on the archaeological manifestations of that proposed migration.

If the Japanese dialects, including Ryukyuan, can be derived from a common language of the last few centuries B.C. or the early centuries A.D., then it seems highly probable that their spread through the archipelago was accomplished by the expansion of Yayoi agriculturalists. Supporting archaeological evidence for this Yayoi expansion can be found in the archaeological record of the main islands (see Hudson, n.d.). Interestingly, however, the Ryukyus are more of a problem since many scholars stress their cultural and biological continuities. Biological similarities between the Ainu and the Ryukyuans were noticed very early (e.g., Baelz, 1911) and cultural links have also been reported (Umehara, 1991).

Biologically the Okinawans have a complex heritage. Both the Ainu and Okinawans are thought to retain Archaic Mongoloid traits known in Jomon populations (Hanihara, K., 1986, pp. 82-83; Hanihara, T., 1991), but Okinawans also have a predominant Neo-Mongoloid component derived from Yayoi and later immigration (Kozintsev, 1990, p. 261, 1992). Some gene flow obviously occurred into the Ryukyu Islands, probabiy during the Late Shellmound period which corresponds to the Yayoi-Heian eras in mainland Japan.

The beginning of the Late Shellmound period marks an important transition in the Ryukyus. Site numbers increase and display a broadened subsistence base. 
Pottery shapes reflect mainland Yayoi vessels and Yayoi pottery from Kyushu has been found at several sites (Pearson, n.d.). A trade in tropical shells for bracelets also developed between the islands and Kyushu (Pearson, 1990). Evidence for largescale immigration from Kyushu at this time, however, is ambiguous and more work is needed to link language replacement with the population history of the Ryukyus.

\section{CONCLUSIONS}

If Homo sapiens sapiens evolved in Africa about 100,000 years ago and spread from that continent replacing earlier hominids throughout the world, then that human dispersal must have had linguistic implications. In fact many scholars now argue that it was an increased capacity for symbolic and linguistic behavior that gave our species its evolutionary advantage. Previous hominids may have been unable to use complex language at all. This means that at the very least all extant human languages must derive from the early Homo sapiens sapiens languages, possibly from a single language. Some linguistic evidence that all extant languages derive from a common source has been presented (Ruhlen, in press).

Recent work by a number of archaeologists has suggested that population expansion following the development of agriculture may have been the primary cause of the dispersal of human languages in the Holocene. Following Renfrew's (1992a) minimalist principles, language distributions which cannot be attributed to agricultural expansion are very likely the result of much earlier, Pleistocene dispersals. There may only have been one such Pleistocene dispersal: "The principle of parsimony invoked here suggests that we should prefer one wave to several, unless we can see clearly how - that is, by what ecological factors - second and successive 'waves' might be propagated.... Until such arguments are formulated, it may be preferable to think of one major episode of the adaptive radiation of our species from Africa" (Renfrew, 1992a, p. 17).

Although they are based on several assumptions which are by no means unanimously accepted, these principles of language dispersal are nevertheless a powerful analytical tool in hypothesizing about linguistic prehistory. When applied to Japan they suggest a number of interesting possibilities. Firstly, it seems likely that language replacement accompanied agricultural expansion in the Yayoi. This hypothesis is supported by the biological and archaeological evidence as well as by the distribution of Japanese dialects. ${ }^{4}$ This "subsistence-demography" model also to my mind rules out any sort of creolization between existing Jomon hunter-gatherer languages and the incoming agricultural one - a concept which has been so central

4 The archaeological evidence for population changes in the Yayoi is often ambiguous, but the fact that both the biological and linguistic records seem to support large-scale immigration suggests we need to look very carefully at the archaeological interpretations, something which cannot be attempted here. Further support for the rather sweeping claims made in this article can be found in the author's forthcoming Ph.D. thesis. 
to the Japanese literature.

The big problem with this Yayoi replacement model is the source of the new language. Theoretically, of course, it could be a language that had existed in north Kyushu for some time and for this reason we cannot totally dismiss Miller's Sobata theory in its broad outlines. Another possibility is a link with the north Korean PuyoKoguryo languages. Here, while the linguistic relationship with Japanese is undoubtedly close, the main difficulty is cultural since Yayoi Japan was mainly influenced by the southern peninsula.

Japanese is widely thought to be an Altaic language, or at least closely related to the Altaic family, and a full understanding of the origins of Japanese needs to take account of the linguistic prehistory of East Asia as a whole. This is a complex problem with a large, though uneven, literature and only a few comments are possible here:

(1) Homelands. The location of the original Altaic homeland has never been the same subject of debate as its Indo-European counterpart, but many Altaicists seem to accept two basic premises. The first of these is that because of ancient contacts with Uralic, Indo-European and Dravidian (in that order of acceptability) the Altaic family originated in the west of its present distribution (Menges, 1968, 1977; Miller, $1980,1989,1990)$. The second point is that the original Altaic expansions were linked with the rise of nomadic pastoralism on the steppes and thus were quite late. Following Menges, Miller (1989, p. 14) argues that Altaic speakers moved east to a second homeland around the Altai mountains at about 2000 B.C. yet he continues to link the arrival of Altaic speakers in Japan with Sobata comb-incised ceramics. While Miller (1990, p. 16) himself notes this pottery dates to well before 3000 в.C., he does not appear to accept the implications for his overall Altaic model.

(2) Divergence. Could Japanese have diverged from proto-Altaic in two to three thousand years? This is a question that needs to be tackled by qualified linguists, but such a short time-depth seems incompatible with the general confusion over the genetic relationship of Japanese.

If the answer to the previous question is no, then two possibilities present themselves. The first is that the Altaic hypothesis is incorrect. Many linguists, of course, do not support the classic view of a proto-Altaic unity (cf. Poppe, 1965, pp. 148-54). We are reminded of Unger's statement (quoted above) that connections between Japanese, Korean, and Tungusic are of a different order than those between the other Altaic branches. It is not impossible, therefore, that this "Macro-Tungusic" sub-group represents an early dispersal which was followed much later by the expansion of a Turkic and Mongolian branch from the western steppes. What we need in order to test this hypothesis is a workable family tree of the languages concerned. To an outsider it seems one reason we do not yet have such a genealogy 
is that until now classification has tended to proceed from smaller units to larger whereas, following the principles outlined by Ruhlen (1987), it seems desirable that the opposite approach be adopted.

A second possible way of getting around the apparent short divergence time for Altaic would be to argue that the real time-depth is much longer. Following Renfrew's principles, however, we would need to tie in any earlier Altaic dispersal with a suitable ecological explanation for human migration. Could Altaic (or a Tungusic-Korean-Japanese branch of Altaic) have been a Pleistocene dispersal into East Asia? Again a greater understanding of the wider linguistic relations across Eurasia, perhaps within the concept of macro-families such as Nostratic and Eurasiatic, seems essential.

(3) Ainu. On the Tohoku place-name evidence and on the general cultural continuities, Ainu seems to me to be descended from an ancient language in the Japanese archipelago and is unlikely to have arrived after the Yayoi. In this case the chances are high that it is descended from a language of the initial Pleistocene colonization of the region. If Ainu is related to Korean and/or Japanese then those languages could also belong to a Pleistocene eastern branch of "Altaic" - or Eurasiatic if that term is more appropriate. The status of the so-called Paleosiberian languages is obviously relevant here, as is the work of linguists who see an Austronesian or Austric derivation for Ainu. The Austronesian hypothesis has the advantage of appearing to fit with the biological evidence for a southern origin for the Jomon Archaic Mongoloid populations. One thing is clear: since Ainu seems to be a very ancient language in the region, an understanding of its development and linguistic relationships is crucial to a full picture of early human dispersals in East Asia.

In his summary of the Altaic panel at the 1987 Workshop on Linguistic Change and Reconstruction Methodology, Unger (1990a) argues that in comparative linguistics "small can be ... beautiful" and that "language history is not a big empty canvas to be filled with broad brushstrokes and daring, sweeping lines, but a broken mosaic that must be reassembled methodically, bit by bit." It seems to me that there is a good case to be made for the opposite approach, that big is indeed beautiful: "In classificatory work it is far better to err by comparing too many languages than too few, so where there is legitimate doubt about the boundary of some genetic group, an investigator would be well advised to include in his study any possible member of the group" (Ruhlen 1987, p. 253). Archaeology and biological anthropology have a major role to play in understanding the big picture and we must not let the enormity of the problem dwarf the real issue of a general understanding of the human past. 


\section{ACKNOWLEDGEMENTS}

I wish to express my gratitude to Prof. John Maher of the International Christian University and to Dr. Peter Bellwood of the Australian National University who both read and commented upon earlier drafts of this paper. Useful references were provided by Mrs. Yuko Yoneda of the Nibutani Ainu Language School. Needless to say, none of these people should be held responsible for the views expressed here.

\section{REFERENCES}

Aston W.G. (1879) A comparative study of the Japanese and Korean languages. J. Royal Asiatic Soc. of Great Britain and Ireland, New Ser. 11.

Baelz, E. von (1911) Die Riu-Kiu-Insulaner, die Aino und andere Kaukasierähnliche Reste in Ostasien. Korrespondenz-Blatt der Deutschen Gesellschaft für Anthropologie, Ethnologie und Urgeschichte 42, 187-191.

Barnes, G.L. (1988) Protohistoric Yamato: Archaeology of the First Japanese State. University of Michigan Center for Japanese Studies and Museum of Anthropology, University of Michigan, Ann Arbor.

Barnes, G.L. (1990) Early Korean states: A review of historical interpretation. In Hoabinhian, Jomon, Yayoi, Early Korean States. Bibliographic Reviews of Far Eastern Archaeology 1990 (Barnes, G.L., ed.), Oxbow Books, Oxford, pp. 113-153.

Bellwood, P.S. (1987) The prehistory of Island Southeast Asia: A multidisciplinary review of recent research. J. World Prehist. 1, 171-224.

Bellwood, P.S. (1990) Foraging towards farming: A decisive transition or a millennial blur? Rev. of Archaeol. 11, 14-24.

Bellwood, P.S. (1991) The Austronesian dispersal and the origin of languages. Sci. Am. 265, 88-93.

Bellwood, P.S. (1992) Southeast Asia before History. In The Cambridge History of Southeast Asia, Vol. 1 (Tarling, N., ed.), Cambridge Univ. Press, Cambridge, pp. 55-136.

Bellwood, P.S. (in press) Population dispersals from East Asia: Archaeological and linguistic evidence for the Southeast Asia connection. In Prehistoric Mongoloid Dispersals (Akazawa, T., and Szathmary, E., ed.), Oxford Univ. Press, Tokyo.

Benedict, P.K. (1990) Japanese/Austro-Tai, Karoma, Ann Arbor.

Boller, A. (1857) Nachweis, dass das Japanische zum Ural-Altaischen stämme gehort, Vienna.

Chamberlain, B.H. (1887) The language, mythology and geographical nomeclature of Japan, viewed in the light of Aino studies. Memoirs of the Literature College, Imperial Univ. of Japan 1.

Chew, J.J. (1976) The prehistory of the Japanese language in the light of evidence from the structures of Japanese and Korean. Asian Perspectives 19, 190-200.

Chew, J.J. (1989) The significance of geography in understanding the relationship of Japanese to other languages. Bochumer Jahrbuch zur Ostasienforschung 12, I, 13-49.

Crystal, D. (1987) The Cambridge Encyclopedia of Language, Cambridge Univ. Press, Cambridge.

Dodo, Y., and Ishida, H. (1990) Population history of Japan as viewed from cranial nonmetric variation. J. Anthrop. Soc. Nippon 98, 269-287.

Edwards, W. (1983) Event and process in the founding of the Japanese: The horserider theory in archaeological perspective. J. Japanese Studies 9, 265-95.

Fujimoto, T. (1988) Mo Futatsu no Nihon Bunka, Tokyo Univ. Press, Tokyo.

Fukuda, Y. (1965) Nara Jidai Togoku Hogen no Kenkyu, Fukan Shobo, Tokyo.

Gjerdman, O. (1926) Word parallels between Ainu and other languages. Le Monde Oriental 20 , 
$27-84$.

Hanihara, K. (1986) The origin of the Japanese in relation to other ethnic groups in East Asia. In Windows on the Japanese Past: Studies in Archaeology and Prehistory (Pearson, R., ed.), Center for Japanese Studies, Univ. of Michigan, Ann Arbor, pp. 75-83.

Hanihara, K. (1991) Dual structure model for the population history of the Japanese. Japan Review 2, 1-33.

Hanihara, T. (1991) Dentition of the Nansei islanders and peopling of the Japanese archipelago: The basic populations in East Asia, IX. J. Anthrop. Soc. Nippon 99, 399-409.

Hattori, S. (1954) 'Gengonendaigaku' sunawachi 'goi tokeigaku' no hoho ni tsuite: Nihon sogo no nendai [On the method of glottochronology and the time depth of proto-Japanese]. Gengo Kenkyu 26/27, 29-77 (English summary pp. 74-77).

Hattori, S. (1959) Nihongo no Keito, Iwanami, Tokyo.

Hattori, S. ed. (1964) Ainugo Hogen Jiten, Iwanami, Tokyo.

Hattori, S. (1976) Ryukyu hogen to hondo hogen. In Okinawagaku no Reimei, Okinawa Bunka Kyokai, Tokyo, pp. 7-55.

Hokama, S. (1977) Okinawa no gengo to sono rekishi. In Iwanami Koza: Nihongo, Vol. 11 (Ono, S., and Shibata, T., ed.), Iwanami, Tokyo, pp. 181-233.

Hudson, M.J. (1990) From Toro to Yoshinogari: Changing perspectives on Yayoi period archeology. In Hoabinhian, Jomon, Yayoi, Early Korean States. Bibliographic Reviews of Far Eastern Archaeology 1990 (Barnes, G.L., ed.), Oxbow Books, Oxford, pp. 63-111.

Hudson, M.J. (1992) Tamil and Japanese: Ono's Yayoi theory. Asian \& Pacific Quart. of Cult. and Soc. Affairs 24, 48-64.

Hudson, M.J. (n.d.) Japanese Ethnogenesis: An Archaeological Study. Ph.D. thesis in preparation, Australian National University.

Inoue, F. (1992) Hogen no tayosei to Nihon bunka no nagare. Nihongogaku 11, 57-67.

Izui, H. (1952) Nihongo to Nanto shogo. Minzokugaku Kenkyu 17, 15-26.

Kamimura, Y. (1965) Okinawa no hogen. Bungaku 33, 722-26.

Kazar, L. (1980) Japanese-Uralic Language Comparison: Locating Japanese origins with the help of Samoyed, Finnish, Hungarian, etc.: An attempt, Lajos Kazar-Tsurusaki Books, Hamburg.

Kazar, L. (1989) Northern Inner Asia: Probable one-time home of the Japanese, Uralians and Altaians. Bochumer Jahrbuch zur Ostasienforschung 12, I, 149-184.

Kindaichi, K. (1937) Kokugo to Ainugo no Kankei. Reprinted in Ainugo kenkyu: Kindaichi Kyosuke Senshu, Vol. 1, Sanseido, Tokyo.

Kirihara, T. (1989) Tsumi'ishizuka to Toraijin, Tokyo Univ. Press, Tokyo.

Komoto, M. (1986) Nihon no kodai bunka to Chosen-hanto. In Nihonjin no Kigen (Hanihara K., ed.), Shogakukan, Tokyo, pp. 107-122.

Kozintsev, A. (1990) Ainu, Japanese, their ancestors and neighbours: Cranioscopic data, J. Anthrop. Soc. Nippon 98, 247-267.

Kozintsev, A. (1992) Prehistoric and recent populations of Japan: Multivariate analysis of cranioscopic data. Arctic Anthropol. 29, 104-111.

Kudo, M. (1989) Josaku to Emishi, New Science, Tokyo.

Ledyard, G. (1975) Galloping along with the horseriders: Looking for the founders of Japan. $J$. Japanese Studies 1, 217-54.

Lee, K-M. (1958) A comparative study of Manchu and Korean. Ural-Altaische Jahrbücher 30, 104-20.

Lee, K-M. (1964) Mongolian loan-words in Middle Korean. Ural-Altaische Jahrbücher 35, 188-97. 
Lewin, B. (1973) Japanese and the language of Koguryo. Papers of the C.I.C. Far Eastern Language Institute 4, 19-33.

Lewin, B. (1976) Japanese and Korean: The problems and history of a linguistic comparison. $J$. Japanese Studies 2, 389-412.

Maher, J.C. (1991) 'North Kyushu Creole': A hypothesis concerning the multilingual formation of Japanese. International Christian University Public Lecture Bulletin 6, 15-48.

Martin, S.E. (1966) Lexical evidence relating Korean to Japanese. Language 42, 185-251.

Menges, K.H. (1968) The Turkic Languages and Peoples: An Introduction to Turkic Studies, Otto Harrassowitz, Wiesbaden.

Menges, K.H. (1975) Altajische Studien, II, Japanisch und Altajisch, Franz Steiner GMBH, Wiesbaden.

Menges, K.H. (1977) Dravidian and Altaic. Anthropos 72, 129-79.

Miller, R.A. (1967) The Japanese Language, Univ. of Chicago Press, Chicago.

Miller, R.A. (1971) Japanese and the Other Altaic Languages, Univ. of Chicago Press, Chicago.

Miller, R.A. (1980) Origins of the Japanese Language, Univ. of Washington Press, Seattle and London.

Miller, R.A. (1982) Japan's Modern Myth: The Language and Beyond, Weatherhill, New York and Tokyo.

Miller, R.A. (1989) Where did Japanese come from? Asian \& Pacific Quart. of Cult. and Soc. Affairs 21, 1-25.

Miller, R.A. (1990) Archaeological light on Japanese linguistic origins. Asian \& Pacific Quart. of Cult. and Soc. Affairs 22, 1-26.

Miller, R.A. (1992) New light on Old Korean. Asian \& Pacific Quart. of Cult. and Soc. Affairs 24, $1-21$.

Mizunoe, K. (1992) Sobatashiki doki no seiritsu. Kikan Kokogaku 38, 75-78.

Murayama, S. (1976) The Malayo-Polynesian component in the Japanese language. J. Japanese Studies 2, 413-436.

Murayama, S. (1992) Ainugo no Kigen, San'ichi Shobo, Tokyo.

Obayashi, T. (1991) The ethnological study of Japan's ethnic culture: A historical survey. Acta Asiatica 61, 1-23.

Oikawa, M. (1933) Minami Chosen Makinoshima Tosando kaizuka. Kokogaku 4-5.

Ono, S. (1957) Nihongo no Kigen, Iwanami, Tokyo.

Ono, S. (1970) The Origin of the Japanese Language, Kokusai Bunka Shinkokai, Tokyo.

Ono, S. (1980) Nihongo no Seiritsu. Nihongo no Sekai 1, Chuokoronsha, Tokyo.

Ono, S. (1990) Yayoi bunka to minami Indo. In Yayoi Bunka to Nihongo, Kadokawa Shoten, Tokyo, pp. 10-49.

Patrie, J. (1982) The Genetic Relationship of the Ainu Language. Oceanic Linguistics Special Publication No. 17, Univ. of Hawaii Press, Honolulu.

Pearson, R.J. (1990) Chiefly exchange between Kyushu and Okinawa, Japan, in the Yayoi period. Antiquity 64, 912-22.

Pearson, R.J. (1992) Ancient Japan, George Braziller, New York and The Smithsonian Institute, Washington D.C.

Pearson, R.J. (n.d.) The place of Okinawa in Japanese historical identity. In Multicultural Japan: Palaeolithic to Postmodern (Denoon, D., Hudson, M., McCormack, G., and Morris-Suzuki, T., ed.). (forthcoming)

Polivanov, E.D. (1924) Toward work on musical accentuation in Japanese (in connection with the Malayan languages). Reprinted in Selected Works (compiled by A.A. Leonte'v.), Mouton, The Hague, 1974. 
Poppe, N. (1960) Vergleichende Grammatik der altaischen Sprachen. Teil I, Vergleichende Lautlehre, Otto Harrassowitz, Wiesbaden.

Poppe, N. (1965) Introduction to Altaic Linguistics, Otto Harrassowitz, Wiesbaden.

Ramstedt, G.J. (1949) Studies in Korean Etymology, Suomalais-Ugrilainen Seura, Helsinki.

Renfrew, C. (1987) Archaeology and Language: The Puzzle of Indo-European Origins, Jonathan Cape, London.

Renfrew, C. (1989) Models of change in language and archaeology. Trans. Philological Soc. 87, 103-55.

Renfrew, C. (1991) Before Babel: Speculations on the origins of linguistic diversity. Cambridge Archaeol. J. 1, 3-23.

Renfrew, C. (1992a) World languages and human dispersals: A minimalist view. In Transition to Modernity: Essays on Power, Wealth and Belief (Hall, J.A., and Jarvie, I.C., ed.), Cambridge Univ. Press, Cambridge, pp. 11-68.

Renfrew, C. (1992b) Archaeology, genetics and linguistic diversity. Man (N.S.) 27, 445-478.

Ro H-J. (1992) A revised framework for Korean prehistory. In Pacific Northeast Asia in Prehistory (Aikens, C.M., and Rhee S-N, ed.), Washington State Univ. Press, Pullman, pp. 209-213.

Ruhlen, M. (1987) A Guide to the World's Languages, Vol. 1, Classification, Stanford Univ. Press, Stanford.

Ruhlen, M. (in press) Multiregional evolution or 'Out of Africa'?: The linguistic evidence. In Prehistoric Mongoloid Dispersals (Akazawa, T., and Szathmary, E., ed.), Oxford Univ. Press, Tokyo.

Sakiyama, O. (1989) Nagai rekishi wo motsu Nihongo wa 'keitoron' de osamaranai kongogo de aru. Kikan Yamataikoku 38, 168-71.

Sasaki, K. (1991) Nihonshi Tanjo, Shueisha, Tokyo.

Sherratt, A., and Sherratt, S. (1988) The archaeology of Indo-European: An alternative view. Antiquity 62, 584-95.

Shibatani, M. (1990) The Languages of Japan, Cambridge Univ. Press, Cambridge.

Shinmura, I. (1911) Kokugo keito no mondai. Taiyo 17. Reprinted in Nihongo no Keito (Ono, S., ed.), Special issue of Gendai no Esupuri, 1980, pp. 35-42.

Shnirelman, V.A. (1988) Historical linguistics through the eyes of the non-linguist. Paper presented at the Conference on Language in Prehistory, University of Michigan, November 1988.

Shnirelman, V.A. (1989) Vozniknovenie Proizvodjasoego Xozjaistva, Nauka, Moscow.

Solnit, D. (1992) Review of Benedict (1990). Language 68, 186-196.

Starostin, S.A. (1986) Problema geneticeskoi obscnosti altaiskikh jazykov. Istoriko-kul'turnye kontakty narodov altaiskoi jazykovoi obscnosti. Tezisy dokladow XXIX sessii Postoiannoi Mezdunarodnoi Altaisticeskoi konferencii [PIAC], 2, 94-112. Moscow.

Starostin, S.A. (1991) Altajsaja Problema i Proisxozhenije Zhaponskogo Jazyka, Moscow. von Strahlenberg, P.J. (1730) Das nord- und östliche Theil von Europa und Asia, Stockholm.

Takahashi N. (1989) Todoroki-shiki doki saiko [A reconsideration of Todoroki type pottery]. Kokogaku Zasshi 75, 1-39 (English summary p. 127).

Umehara, T. (1991) The Japanese view of the "other world": Japanese religion in world perspective. Japan Review 2, 161-90.

Unger, J.M. (1990a) Summary report of the Altaic panel. In Trends in Linguistics. Studies and Monographs 45. Linguistic Change and Reconstruction Methodology (Baldi, P., ed.), Mouton de Gruyter, Berlin and New York, pp. 479-482.

Unger, J.M. (1990b) Japanese and what other Altaic languages? In Trends in Linguistics. Studies and 
Monographs 45. Linguistic Change and Reconstruction Methodology (Baldi, P., ed.), Mouton de Gruyter, Berlin and New York, pp. 547-561.

Whymant, A.N. (1926) The Oceanic theory of the origin of the Japanese language and people. Trans. Asiatic Soc. Japan (2nd ser.) 3, 15-81.

Yamada, H. (1982-83) Ainugo Chimei no Kenkyu, Vols. 1-4, Sofukan, Tokyo.

Yasuda Y. (1991) Influences of the vast eruption of Kikai Caldera Volcano in the Holocene vegetaional history of Yakushima, southern Kyushu, Japan. Japan Review 2, 145-160.

Zvelebil, M., and Zvelebil, K.V. (1988) Agricultural transition and Indo-European dispersals. Antiquity 62, 574-83. 